\title{
Kinetic Mechanism of DNA Translocation by the RSC Molecular Motor
}

\author{
Allen Eastlund, Shuja Shafi Malik, and Christopher J. Fischer \\ Department of Physics and Astronomy, University of Kansas, 1251 Wescoe Hall Dr., 1082 Malott \\ Hall, Lawrence, KS 66045 USA
}

\begin{abstract}
ATP-dependent nucleosome repositioning by chromatin remodeling enzymes requires the translocation of these enzymes along the nucleosomal DNA. Using a fluorescence stopped-flow assay we monitored DNA translocation by a minimal RSC motor and through global analysis of these time courses we have determined that this motor has a macroscopic translocation rate of 2.9 $\mathrm{bp} / \mathrm{s}$ with a step size of $1.24 \mathrm{bp}$. From the complementary quantitative analysis of the associated time courses of ATP consumption during DNA translocation we have determined that this motor has an efficiency of 3.0 ATP/bp, which is slightly less that the efficiency observed for several genetically related DNA helicases and which likely results from random pausing by the motor during translocation. Nevertheless, this motor is able to exert enough force during translocation to displace streptavidin from biotinylated DNA. Taken together these results are the necessary first step for quantifying both the role of DNA translocation in nucleosome repositioning by RSC and the efficiency at which RSC couples ATP binding and hydrolysis to nucleosome repositioning.
\end{abstract}

\section{Keywords}

chromatin remodeling enzyme; RSC; DNA translocation; energy transduction; kinetic modeling

\section{Introduction}

Eukaryotic DNA is packaged into chromatin that renders these sequences largely inaccessible for transcription or repair[1,2]. The basic packaging unit of chromatin is the nucleosome which consists of a central histone octamer (two molecules of each of the four core histones: H2A, H2B, H3 and H4) about which approximately 147 base pairs (bp) of DNA is wrapped in 1.67 turns[3,4]. Chromatin structure and by extension gene expression can be regulated either through covalent modification of histone proteins [5,6] or through an ATPdependent mechanism of nucleosome repositioning carried out by a family of molecular motors, termed chromatin remodelers[7-9]; in fact, these two processes are intimately linked as modifications of histones can affect chromatin remodeler function[10-12]. Chromatin remodelers have been grouped into four functionally and structurally similar families: SWI/ SNF, ISWI, NURD/Mi-2/CHD, and INO80[13,14]; members of each family share a conserved ATPase domain, but are differentiated based upon the additional domains within

\footnotetext{
(C) 2013 Elsevier Inc. All rights reserved.

"To whom correspondence should be addressed, The University of Kansas, Department of Physics and Astronomy, 1251 Wescoe Hall Drive, 1082 Malott, Lawrence, KS 66045-7582, Phone: 785-864-4579, Fax: 785-864-5262, shark@ku.edu.

Publisher's Disclaimer: This is a PDF file of an unedited manuscript that has been accepted for publication. As a service to our customers we are providing this early version of the manuscript. The manuscript will undergo copyediting, typesetting, and review of the resulting proof before it is published in its final citable form. Please note that during the production process errors may be discovered which could affect the content, and all legal disclaimers that apply to the journal pertain.
} 
their catalytic subunits[12,15]. There are currently two general models proposed for the process of ATP-dependent nucleosome repositioning[13,16-18]. In one model, translocation of the chromatin remodeler along nucleosomal DNA, or nucleosome flanking DNA, results in the formation of small DNA loops that propagate around the histone octamer giving rise to synchronized DNA translocation and nucleosome repositioning. In the other model, DNA translocation by the chromatin remodeling complex results in the formation of large DNA loops which accumulate on the nucleosome surface creating tension that is eventually released through periodic nucleosome "jumping." Thus, a mechanistic description of DNA translocation by remodelers is required for further modeling of the mechanism of their ATPdependent nucleosome repositioning activity.

Saccharomyces cerevisiae RSC (ㅌemodels the $\underline{\text { Structure of }}$ Chromatin) is an essential SWI/ SNF-family chromatin remodeling enzyme capable of repositioning nucleosomes from the center of DNA fragments toward the ends without disrupting the integrity of the nucleosomes $[19,20]$; RSC under high concentrations has also been shown to be capable of ejecting nucleosomes from the DNA[21]. RSC complex consists of 15 proteins, five of which are highly similar to the subunits of the SWI/SNF complex, and has a molecular weight of approximately $1 \mathrm{MDa}$ [19]. The ability of RSC to translocate along DNA is essential for its nucleosome repositioning activity $[13,22]$ and estimates of $1 \mathrm{bp}$ or $2 \mathrm{bp}$ have been determined for the kinetic step size of DNA translocation by RSC[23]. The results of recent studies have also suggested a two-step mechanism for the repositioning of nucleosomes by RSC in which the formation of a stable complex of DNA, RSC, and the histone octamer serves as an intermediate for the repositioning reaction[24-26]. According to this model, after the initial binding of RSC to the nucleosome, competition between RSC and the histones for binding to the nucleosomal DNA leads to formation of the intermediate complex. This intermediate is characterized by the nucleosomal DNA being associated primarily with RSC and largely dissociated from the histones [25,26]. This (at least partial) unwrapping of the DNA from the histones provides an environment in which the small loops of DNA formed by the DNA translocation of RSC can more easily propagate around the surface of the octamer and subsequently reposition the nucleosome. However, despite the significance of DNA translocation to the nucleosome repositioning activity of RSC and other remodelers [27], details about the mechanism that couples the binding and hydrolysis of ATP to mechanical work remains unclear.

In this study we utilize a truncated construct of RSC, termed 'trimeric minimal RSC' (RSCt), which only contains 3 of the original 15 subunits of full length RSC[23,28]; the subunits are ARP7, ARP9, and a truncated version of STH1. STH1 is the DNA-binding ATPase and translocation motor[28,29] of the construct and ARP7 and ARP9 are nuclear actin related proteins whose interaction with STH1 greatly improves the stability and solubility of the complex[19,29,30]. The truncated construct was utilized because it can be over expressed in Escherichia Coli, unlike the full complex. This allows for increased yields during the purification process. This construct has been used previously by Sirinakis et al. to characterize the translocation properties of the RSC motor domain as well as Malik et al. to study DNA binding.[23,28] In our experiments we monitored the translocation of RSCt along double-stranded DNA using a stopped-flow assay that monitors changes in fluorescence intensity associated with the translocation of RSCt along fluorophore labeled DNA[31-33]. Through global analysis of associated time courses of translocation we were able to determine the macroscopic rate of DNA translocation and associated kinetic step size. Through further analysis of the ATPase activity associated with DNA translocation we were also able to determine the efficiency at which RSCt couples the binding and hydrolysis of ATP to its physical movement along the DNA. This in turn provides a limit on the efficiency at which RSC could couple ATP binding and hydrolysis to nucleosome repositioning. Finally, in a separate assay we monitored the ability of the RSC trimer to 
displace streptavidin from biotinylated DNA [31,34]. The ability of RSC to actively displace the streptavidin demonstrates the large forces that this molecular motor is capable of exerting during translocation and thus, by extension, during nucleosome repositioning

\section{Materials and Methods}

\section{Buffers}

All buffers were prepared with reagent grade chemicals using twice-distilled water that was deionized with a Milli-Q purification system (Millipore Corp., Bedford, MA). The RSCt storage buffer used is $25 \mathrm{mM}$ Tris $\mathrm{HCl}\left(\mathrm{pH} 7.5 @ 25^{\circ} \mathrm{C}\right), 150 \mathrm{mM} \mathrm{KOAC}, 10 \%$ (v/v) glycerol, and $0.5 \mathrm{mM}$ 2-mercaptoethanol. All experiments were conducted in the reaction buffer consisting of $10 \mathrm{mM}$ HEPES (pH $7.0 @ 25^{\circ} \mathrm{C}$ ), $5 \mathrm{mM} \mathrm{MgCl}_{2}, 100 \mathrm{mM} \mathrm{KOAC}, 4 \%$ (v/v) Glycerol, $2.5 \mathrm{mM}$ DTT, and $0.1 \mathrm{mg} / \mathrm{mL}$ BSA.

\section{Oligonucleotide substrates}

All labeled and unlabeled oligonucleotides were purchased from IDT Technologies (Coralville, IA) and were HPLC purified. Each oligonucleotide was extensively dialyzed against Milli-Q water. Double-stranded DNA substrates were annealed by mixing together equal concentrations of complimentary strands in a DNA annealing buffer consisting of 10 $\mathrm{mM}$ HEPES (pH 7.0) and $40 \mathrm{mM} \mathrm{KAC}$. The mixture is then heated to $95^{\circ} \mathrm{C}$ and allowed to cool to room temperature over the course of 12 hours. For fluorophore-labeled DNA, a 5\% overabundance of unlabeled DNA was included to ensure complete annealing of all fluorescein-labeled DNA strands. For all fluorophore-labeled substrates, the fluorophore was attached only at the five-prime (5') end of a single strand of the duplex, leaving the opposing single-stranded mated substrate unlabeled. This allows sampling of only the population of protein translocating along one backbone.

\section{Protein Purification}

RSCt was over-expressed and purified from an Escherichia coli bacterial over-expression system. The CDF Duet-1 vector (Novagen) bearing a Sth1 construct (301-1097aa) with a $10 \mathrm{X}$ histidine tag at the $\mathrm{N}$-terminus was transformed into BL21(DE3) codon plus strain along with the RSF Duet vector (Novagen) containing Arp9 and Arp7 constructs. These were selected on streptomycin and kanamycin plates. The cells were grown in nutrientrich auto-inducible media at $37^{\circ} \mathrm{C}$ for $4 \mathrm{hrs}, 30^{\circ} \mathrm{C}$ for $12 \mathrm{hrs}$ and at $22^{\circ} \mathrm{C}$ for $24 \mathrm{hrs}$, harvested by centrifuging at $6000 \mathrm{~g}$ at $4^{\circ} \mathrm{C}$, resuspended in lysis buffer $(50 \mathrm{mM}$ phosphate buffer $\mathrm{pH} 7.5$, $300 \mathrm{mM} \mathrm{NaCl}, 10 \%$ glycerol, $0.5 \mathrm{mM} \beta$-mercaptoethanol and $1 \mathrm{X}$ protease inhibitors), sonicated at $30 \%$ duty cycle for 30 secs $10-15$ times. The cells were kept on ice at all times. The lysate was then centrifuged at 20,000g for 30 minutes at $4^{\circ} \mathrm{C}$. The supernatant was run on a pre-packed Ni-NTA column pre-equilibrated with $20 \mathrm{mM}$ Tris $\mathrm{pH} 7.5,100 \mathrm{mM} \mathrm{NaCl}$, $10 \%$ glycerol, $0.5 \mathrm{mM} \beta$-mercaptoethanol and $30 \mathrm{mM}$ imidazole. The protein was eluted in a gradient using buffer containing $20 \mathrm{mM}$ Tris $\mathrm{pH} 7.5,100 \mathrm{mM} \mathrm{NaCl}, 10 \%$ glycerol, 0.5 $\mathrm{mM} \beta$-mercaptoethanol and $500 \mathrm{mM}$ imidazole. The protein started eluting at $50 \%$ of the gradient. The purified protein was run on $12 \%$ polyacrylamide gel containing SDS. The purified fractions were pooled, concentrated and then run through a gel filtration column equilibrated with a sizing buffer $(20 \mathrm{mM}$ Tris $\mathrm{pH} 7.5,200 \mathrm{mM} \mathrm{NaCl}, 10 \%$ glycerol, 0.5 $\mathrm{mM} \beta$-mercaptoethanol and $1 \mathrm{X}$ PMSF). The fractions that eluted corresponding to RSCt were pooled and concentrated further and then flash frozen in liquid nitrogen to be stored at $-80^{\circ} \mathrm{C}$. Protein concentration was determined using a Bradford assay comparison to a BSA standard at $595 \mathrm{~nm}$. 


\section{ATPase Assay}

ATPase assay: ATPase activity was measured at $30^{\circ} \mathrm{C}$ by monitoring the hydrolysis of $\left[a^{32} \mathrm{P}\right]$ ATP. The reaction was carried out in a reaction buffer containing 10mM HEPES $\mathrm{pH}$ 7.0, $1 \mathrm{mM}$ ATP, $5 \mathrm{mM} \mathrm{MgCl} 2,20 \mathrm{mM}$ potassium acetate, $4 \%$ glycerol, $0.5 \mathrm{mM}$ DTT and $0.1 \mathrm{mg} / \mathrm{ml} \mathrm{BSA}$. RSCt at $50 \mathrm{nM}$ concentration was pre-incubated with a series of concentrations of double-stranded DNA, ranging from 10 to $1000 \mathrm{nM}$, and the reaction was initiated by the addition of ATP. Aliquots of the reaction samples were removed at fixed time points and quenched with an equal volume of $0.5 \mathrm{M}$ EDTA to stop the reaction. The reaction products were separated by TLC on PEI Cellulose F sheets in $0.6 \mathrm{M}$ potassium phosphate buffer, $\mathrm{pH} 3.4$ and quantized with a PhosphorImager (GE Healthcare). The ATPase time course was analyzed using ImageJ to determine the amount of ATP hydrolyzed.

\section{Streptavidin Displacement Assay}

100 pmol of each DNA length was radio-labeled using 5 units polynucleotide kinase from phage T4 infected E. coli (T4 PK), and $50 \mathrm{uCi}{ }^{32} \mathrm{P} \gamma$-labeled ATP. DNA labeling buffer is $40 \mathrm{mM}$ Tris $\mathrm{HCl}\left(\mathrm{pH} 7.5 @ 25^{\circ} \mathrm{C}\right), 10 \mathrm{mM} \mathrm{MgCl} 2$, and $0.5 \mathrm{mM}$ DTT. The solution was incubated @ $37^{\circ} \mathrm{C}$ for 1 hour before being spun on a GE Illustra ProbeQuant G-50 micro column to remove any remaining $\gamma$-labeled ATP. Prior to initializing the reaction, $20 \mathrm{nM}$ of biotinylated DNA lengths were incubated with $300 \mathrm{nM}$ streptavidin for 30 mins to ensure total saturation of all DNA-biotin sites. After the addition of $20 \mathrm{nM} \mathrm{RSCt}, 3 \mathrm{uM}$ biotin was then included to act as a trap for any free streptavidin or streptavidin that will be displaced by the RSC and was incubated with DNA for $40 \mathrm{~min}$ at $30^{\circ} \mathrm{C}$. Reactions were started upon addition of $5 \mathrm{mM}$ ATP and carried out in $100 \mu \mathrm{L}$ solution volume with $10 \mu \mathrm{L}$ aliquots being removed every 5 minutes for the initial 30 minutes and then at 10 minute intervals until 1 hour had been reached. Reaction aliquots were quenched in equal volumes of quench buffer consisting of $0.6 \%(\mathrm{w} / \mathrm{v})$ SDS, $200 \mathrm{mM}$ EDTA, $0.08 \%(\mathrm{w} / \mathrm{v})$ xylene cyanol, $0.08 \%(\mathrm{v} / \mathrm{v})$ bromophenol blue, $10 \%(\mathrm{v} / \mathrm{v})$ glycerol. To ensure a constant concentration of ATP, a regeneration system was integrated by including 15 units $/ \mathrm{mL}$ rabbit muscle pyruvate kinase (PK), and 18 units $/ \mathrm{mL}$ lactate dehydrogenase (LDH). $2 \mathrm{uL}$ fractions of each time point were analyzed using 6\% TBE Invitrogen Novex gels and electrophoresis was performed using an Invitrogen X-Cell SureLock minicell system with Novex TBE Running Buffer. Voltage was applied with an Invitrogen PowerSure500 power supply and run at constant voltage. Gels were imaged on a GE HealthCare phosphorimager and resulting images were quantitatively analyzed with the ImageJ software package. Streptavidin was stored in a storage buffer consisting of $10 \mathrm{mM}$ HEPES (pH $7.0 @ 25^{\circ} \mathrm{C}$ ), $20 \%$ (v/v) glycerol, and $5 \mathrm{mM} \mathrm{NaCl}$.

\section{Stopped-flow Translocation Assay}

All fluorescence stopped-flow experiments were carried out in the same reaction buffer as ATPase assays, at $30^{\circ} \mathrm{C}$ using an Applied Photophysics SX.18MV-R Stopped-Flow Spectrophotom- eter (Applied Photophysics Ltd., Leatherhead, UK). Optical filters were purchased from ThorLabs (Newton, NJ). Fluorescein-labeled single-stranded DNA was purchased from IDT Technologies (Coralville, IA) along with complementary unlabeled single-stranded DNA. The individual strands were then annealed together as described above. The fluorescein label was excited at $492 \mathrm{~nm}$, and its fluorescence emission was monitored at wavelengths $>520 \mathrm{~nm}$ using a long-pass filter. $200 \mathrm{nM} \mathrm{RSCt}$ was incubated with fluorescein-labeled DNA of varying lengths for 5 min after loading onto one of the syringes of the stopped-flow instrument. These experiments were performed under conditions where the total concentration of the DNA was in excess of the total concentration of RSCt to ensure that the predominant bound species were singly-bound DNA-RSCt complexes. A solution composed of the same reaction buffer listed above and $20 \mathrm{mM}$ ATP was loaded on the other syringe of the stopped-flow instrument. Reaction mixtures in both 
syringes were incubated for $2 \mathrm{~min}$ at $30^{\circ} \mathrm{C}$ to allow for temperature equilibration prior to mixing. Following the 1:1 mixing of the two solutions, the final reaction concentrations were as follows: $100 \mathrm{nM}$ RSCt, $12 \mathrm{M}$ DNA binding site concentration based upon an initially assumed $10 \mathrm{bp}$ binding site size, and $10 \mathrm{mM}$ ATP. The kinetic traces used for analysis are an average of at least 15 individual traces.

\section{Data Analysis}

All analysis performed was NLLS fits using Conlin[35]. All fitting models were written in C and compiled using Microsoft Visual Studio .NET 2003 compiler on a Windows XP workstation. The software library CNL 6.0 (Visual Numerics Incorporated, Houston, TX) was used for the numerical calculation of the inverse Laplace transform. The uncertainties in all fitted parameters reported in this manuscript are the standard deviation of the mean.

During its translocation along double-stranded DNA RSC tracks along a single strand of the duplex with a 3' to 5' directional bias[13,22]. Because of this we can model double-stranded DNA translocation by RSCt as a 3' to 5' directionally biased single-stranded DNA translocation process[36,37]. Initially, we analyzed our translocation time courses using a single-step, multiple-turnover model[33,38,39], but were unable to find a satisfactory description of the data as determined by the variance of fit (data not shown). Since previous work has hinted that possible secondary steps are required for competent RSC translocation $[23,40]$, we derived and implemented another model that included these ancillary steps. This model, shown in Scheme 1, upon binding at a random location, $I_{n}{ }^{*}$, involves an initiation step prior to processive translocation[36,37]. This step could be a conformational change in the protein, a transition between different binding modes[41], etc. This model makes no distinction as to what the physical mechanism could be; only that it is required prior to active movement by RSC. The equation corresponding to Scheme 1 that we used for analysis is given as

$$
f(t)=\mathscr{L}^{-1}\left[A^{*} \frac{1}{((n-1) r+r n+1)}\left(B A+k_{t} r+k s+s-k_{t} r\left(\frac{k t}{s+k_{d}+k_{t}}\right)^{n}+\frac{(r-r n)\left(k_{d}+s\right)}{s\left(k_{d}+s\right)}\right)+\frac{C}{s}\right]
$$

In this equation $\mathrm{L}^{-1}$ denotes the inverse Laplace operator, and $s$ is the Laplace variable. The microscopic rate constants $k_{t}, k_{d}$, and $k_{i}$ are associated with the translocation, dissociation, and initiation processes, respectively. The variable $r$ is the ratio of the initial probability (before the addition of ATP) of RSCt bound to any other position (other than the $3^{\prime}$ or $5^{\prime}$ ends of the single-strands comprising the duplex) on the single-strands to the initial probability of the RSCt bound to the $5^{\prime}$ end of the strands[39,42]. The variable $r n$ is the ratio of the initial probability (before the addition of ATP) of the RSC bound to the $3^{\prime}$ end of the single-strands to the initial probability of the RSCt bound to the $5^{\prime}$ end of the single strands[43]. $A$ is a scalar constant that incorporates both the initial concentration of the protein bound to the single-stranded oligonucleotide and the fluorescence signal change associated with the protein bound at the fluorophore-labeled $5^{\prime}$ end of the DNA. Because the scalar $A$ contains information pertaining to concentrations, it then easily allows for variations in protein concentration, such as when the concentration is halved during stoppedflow cell mixing conditions or protein binding to the non-labeled strand of DNA and producing no signal during translocation. These types of variations would be accounted for simply through a change in signal amplitude, not a change in signal shape or other defining characteristics. $C$ is a scalar offset term that is included for any arbitrary offsets in system signal that is not taken out of the data upon normalization. Because both $\mathrm{A}$ and $\mathrm{C}$ are not global variables, each data set is able to have its own arbitrary scaling factors independent of the other lengths. $B A$ is the ratio of the fluorescence signal change associated with RSCt completing the initiation step and beginning processive translocation. The variable $n$ is 
defined as the number of possible steps the protein can take on a given nucleotide and is given by Equation 2.

$$
n=\frac{L-d}{m}
$$

In Equation 2 the variable $L$ is the total DNA length in basepairs; $m$, the kinetic step size in basepairs; and $d$, the binding site size of RSCt in basepairs.

The model we used for analysis of the time courses collected using the streptavidin displacement assay included the initiation step from Scheme 1 as well as a final step, occurring immediately prior to reaching the end of the DNA, which is associated with the displacement of the streptavidin molecule from its biotin bond; this step is associated with the microscopic rate constant $k_{S}$. The equation corresponding to this model, represented in Scheme 2, is too cumbersome to reproduce here, but its steady-state limit is shown in Equation 3.

$$
f(t)=A^{*} \frac{k_{i}}{\left(k_{d}+k_{i}\right)} \frac{k_{s}^{2}}{\left(k_{d}+k_{s}\right)} \frac{k_{b}}{\left(k_{d}+k_{b}\right)} \frac{1}{1+r(n-1)}\left(1+\frac{r k_{t}}{k_{d}}\left(1-\left(\frac{k_{t}}{k_{d}+k_{t}}\right)\right)\right) t
$$

where the scalar variable $A$ is proportional to the population of initially bound protein.

The equation utilized to analyze the data collected from the ATPase assay was derived in Khaki et al.[43] and is given as

$$
k_{c a t}=\left[c k_{t} r \frac{\left(n(1-P)-P\left(1-P^{n}\right)\right)}{(1+n r)(1-P)}+c_{i} k_{d}\right]\left(\frac{k_{i}}{k_{d}+k_{i}}\right)
$$

where $k_{c a t}$ is the maximum ATPase rate under saturating conditions of nucleic acid. The constants $c$ and $c_{i}$ are the ATP coupling stoichiometries; $c$ is defined as the number of ATP consumed per translocative step while $c_{i}$ refers to the ATP consumed per initiation step. $P$ is the processivity defined as

$$
P=\frac{k_{t}}{k_{t}+k_{d}}
$$

and is a unitless measure of a protein's translocation ability[32,43-45] The processivity can also be used to determine the average number of basepairs translocated by RSCt before dissociation from the DNA

$$
m^{*} \frac{P}{1-P}
$$

This calculation is equivalent to the processivity as defined in Sirinakis et al.[23

\section{Computer simulations}

To further examine potential interactions of microscopic processes and their effect on the data-fitting parameters for experimental results, we performed a series of computer simulations in which we incorporated non-uniformity into the motion of individual proteins along the DNA $[36,37,46]$. Using these simulations we generated synthetic data sets which we could then subsequently analyze with our model equations to determine the effects of non-uniform motion and other perturbations on the parameters determined from this analysis. These simulations were written in $\mathrm{C}$ and compiled using Microsoft Visual Studio .NET 2003 compiler on a Windows XP workstation. 


\section{Results}

The results of several previously published independent experiments have demonstrated that RSC is an ATP-dependent double-stranded DNA translocase [22]. During its translocation along double-stranded DNA RSC tracks along only one strand of the duplex with a 3' to 5' directional bias $[13,22]$. Furthermore, the ability of RSC to translocate along DNA is fundamental to its ability to reposition nucleosomes [13]. In order to gain further insight into the physical process of DNA translocation including the associated mechanism through which the energy obtained from the binding and hydrolysis of ATP by RSCt are coupled to the physical movement of the enzyme along the DNA we conducted a series of independent experiments designed to determine the kinetic mechanism of DNA translocation by the enzyme.

\section{RSCt Is a Viable Translocase}

In our first set of experiments we determined the dependence of the steady-state rate of the DNA stimulated ATPase activity of RSCt on DNA length. Using an estimated $10 \mathrm{bp}$ binding site[22], we began by establishing the concentration of DNA binding sites that corresponded to maximal stimulation of RSCt's ATPase activity (data not shown) and found it to be 10.2 $\mu \mathrm{M}$; since these experiments are multiple turnover experiments in which RSCt experiences several rounds of DNA binding, DNA translocation, and dissociation all DNA concentrations are presented in terms of binding sites[40]. All subsequent experiments were performed under identical saturating DNA concentrations. The results of a series of DNAstimulated ATPase assays with RSCt and different lengths of DNA are shown in Figure 1A; the solid lines in Figure 1A are linear fits of this data used to determine the apparent $k_{c a t}$ for each DNA length. As shown in Figures 1A and 1B, the steady-state ATPase rate increases with increasing length of DNA, consistent with RSCt being a DNA translocase[40]. Indeed, since all of these experiments were conducted under conditions of equal RSCt binding site concentrations, the DNA length dependent differences in the ATPase rate are not a trivial consequence of a DNA length dependent change in the binding rate of the enzyme[40]; i.e., a faster ATPase rate for longer DNA substrates is not a result of those substrates having more RSCt binding sites and thus a faster rebinding rate for dissociated RSCt.

A determination of the efficiency at which this ATPase activity is coupled to DNA translocation requires an additional determination of the kinetic mechanism of DNA translocation by RSCt. Since RSC tracks along a single strand of the duplex during DNA translocation we monitored the translocation of RSCt along DNA using a modified form of a single-stranded DNA translocation assay[36,38,39]. In these experiments, a pre-incubated solution containing RSCt and double-stranded fluorophore-labeled DNA is rapidly mixed with ATP and the subsequent time course of fluorophore florescence intensity is monitored. Since the interaction of RSCt with the fluorophore results in a quenching of its fluorescence intensity (Figure 2A and B) the resulting time course is directly correlated with the translocation of RSCt along DNA[33,38].

As shown in Figure 2B the time courses of fluorescence observed in these experiments consisted of several phases: the first phase is a rapid decrease in the fluorescence intensity of the fluorophore. Given that this signal change was present even in the absence of ATP (Figure 2A), we attribute this phase to processes not associated with the translocation of RSCt along the DNA (e.g., a redistribution of free and bound RSCt following the mixing and dilution of the sample in the stopped-flow instrument). Additional phases are observed only in the presence of ATP and are associated with further decreases in fluorescence intensity of the fluorophore. Since time courses of these changes depend upon the length of the DNA (Figure 2B), they are associated with the ATP-dependent directionally-biased translocation of RSCt along the DNA [22,38,39]; In order to avoid the presence of ATP- 
independent processes affecting the analysis of the ATPdependent translocation, we restricted our analysis to the portions of the time courses occurring after the first 0.5 seconds of the mixing reaction. There is no longer any change in the fluorescence time courses observed in the absence of ATP in this region (Figure 2A).

In previous applications of this assay to monitor the translocation of helicases along singlestranded DNA, a protein trap was included with the ATP to prevent rebinding of dissociated protein to DNA [42]; this ensures that only single-turnover DNA-binding kinetics were observed. The inclusion of a protein trap in our experiments resulted in rapid and total dissociation of RSCt from the DNA because of the ability of the trap to actively displace RSCt from the DNA (data not shown); active displacement of DNA translocases by protein traps has been previously observed $[36,39,42]$. Because of this, we were unable to monitor DNA translocation by RSCt in the presence of a protein trap and thus the time courses that we observe are influenced by both pre-steady state and steady-state kinetics. To minimize the complications associated with analyzing these data we conducted all experiments using equal concentrations of total DNA binding sites for RSCt for each DNA length[40] and thus the kinetics of DNA binding by initially free and dissociated RSCt are the same for each length of DNA. Interestingly, we still see length-dependent changes in the data indicating a contribution from pre-steady state kinetics. If these time courses were completely dominated by the steady-state signal, the traces would necessarily be the same for all lengths of DNA.

In our first attempt to analyze these translocation time courses we used a multiple turnover translocation model as derived in Fischer et al. (2004)[33,38,39] In this model RSCt is assumed to bind randomly, but uniformly, to the DNA; we ignore any potential variations in binding affinity of RSCt near the ends of the DNA associated with differences in counterion condensation at the ends $[43,47,48]$. RSCt is initially bound in a random location, $i$ translocation occurs steps away from the end of the DNA, where $i$ is constrained between the values of 1 and $n$, the maximum number of translocation steps required for RSCt to move from one end of the DNA to the other. Upon addition of ATP to the system, RSCt translocates along the DNA, tracking along one strand of the duplex with 3' to 5' directionality[17,22], through a series of repeated rate-limiting translocation steps with associated microscopic rate constant $k_{t}$. During each rate-limiting step RSCt moves $m$ basepairs along the DNA and hydrolyzes $c$ ATP molecules; the microscopic parameter $m$ is referred to as the kinetic step size[37,40]. The microscopic rate constant for dissociation during translocation is $k_{d}$. All initially free and dissociated RSCt can bind the DNA with a rate constant $k_{b}$.

This model was unable to provide a constrained fit to the time courses (data not shown). This suggests that an additional process, not included in this model, is occurring during DNA translocation [38]. Based upon previous studies of other DNA translocases the two likely candidates for this additional process are either an initiation step preceding processive translocation[40] or a dissociation event from the end of the DNA that is different from the other dissociation process $[39,43]$. Unfortunately, we were unable to derive time-dependent expressions for the population of protein at the end of the DNA associated with these models for arbitrary lengths of the DNA (i.e., for arbitrary values of $n$ ). Since determining the kinetic step size of translocation requires analyzing the dependence of $n$ on the length of the DNA[36,37] we instead analyzed these time courses using Scheme 1 (Equation 1). In this analysis, effects of all processes not associated with the processive translocation of the enzyme (initiation, rebinding of dissociated RSCt, etc.) are related within the single parameter $k_{i}$. Analysis of computer simulated time courses of DNA translocation using this approach confirmed that this approach resulted in correct estimates of $m, k_{t}$, and $k_{d}$ for these data sets, but that estimated values of $k_{i}$ were dependent upon the rates for all the processes not associated with processive translocation (the rate of rebinding, the rate of initiation, etc.). 
For this reason, estimates of $k_{i}$ determined from the analysis of our time courses are influenced by both initiation and rebinding processes of RSCt. The results of simultaneous global NLLS of all kinetic time courses to Scheme 1 (Equation 1) are shown in Figure 2B and Table 1. This analysis provides a good description of the time courses as judged by the variance of the fit, and returns a value of $(2.3 \pm 0.1) \mathrm{bp} / \mathrm{s}$ for the macroscopic rate of DNA translocation with a processivity and kinetic step size of $(0.92 \pm 0.01)$ and $(1.24 \pm 0.18) \mathrm{bp}$, respectively.

\section{ATP Hydrolysis Is Weakly Coupled To DNA Translocation}

To determine the stoichiometry of ATP binding and hydrolysis associated with DNA translocation by RSCt we also analyzed the ATPase activity of RSCt during translocation (Figures 1 and 2) according to Scheme 1. In each round of translocation, as the protein moves from position $I_{i}$ to $I_{i-1}$, (rate constant $k_{t}$ from Scheme 1) it uses the energy from ATP hydrolysis[19]. Similarly, during the combined slow-step phases modeled in Scheme 1 (rate constant $k_{i}$ ) we allow for ATP hydrolysis to also occur in combination with the slow-step phases. Utilizing an ATPase model based upon the possibility of equal probabilities of binding along the double-stranded substrate along with a pausing step derived in Khaki et al. [43] and shown in Scheme 3, we were able to fit to this model (Equation 4) and thereby distinguish contributions to ADP production from either translocation or the aggregated slow processes. In our analysis of the data in Figure 1B using Equation 4 we fixed the values of $k_{t}, k_{d}, k_{i}, r, m$, and $d$ to those determined from our previous NLLS analysis of our fluorescence translocation time courses (Figure 2B and Table 1). The solid line in Figure 1B is the result of this analysis which returned a value of $c=(3.77 \pm 0.02)$ ATP per step which corresponds to an ATP utilization rate of $(3.0 \pm 0.4)$ ATP/bp for DNA translocation by RSCt. Furthermore, we also determine that during any aggregated pausing-step phases (associated with the effective rate constant $k_{i}$ step in Scheme 1), it utilizes $(11.69 \pm 0.11)$ ATP per step. As shown in Scheme 3, this constant corresponds to the value of $c_{i}$ in Table 1 which is a measure of the number of ATP utilized in the aggregate slowstep phases.

However, since we are unable to determine estimates of the individual kinetic steps that are absorbed into $k_{i}$, we are unable to determine the amount of ATP utilized per individual step within that group of processes.

\section{RSCt Is Capable Of Disrupting the Streptavidin-Biotin Interaction in A DNA Length- Dependent Manner}

Finally, in an effort to qualitatively assess the forces that RSCt exerts during DNA translocation, we monitored the ability of translocating RSCt to displace streptavidin from biotinylated DNA. A similar assay has been used to quantify the DNA translocation activity of viral helicases[34]. The streptavidin-biotin interaction has one of the strongest binding affinities in nature, with an affinity on the order of $10^{-14} \mathrm{M}[49]$ and thus the ability of RSCt to disrupt this interaction can be used as a qualitative measurement of the minimum potential force that RSCt can apply during DNA translocation. We performed assays involving 40 and 80 bp double stranded DNA molecules that had been biotinylated at the 5' end of one strand while the other end of the complimentary strand was left available for radiolabeling. As described in Materials and Methods, we then monitored the streptavidinbiotin-DNA concentrations versus free DNA over the course of an hour to examine the change in populations. In the absence of RSCt or ATP there was no change in the population of streptavidin-bound complexes. However, when ATP was added to the reaction there was a significant change in the amount of free DNA in solution (Figure 3A).

Another interesting characteristic of this experiment is that the displacement activity of RSCt is also length-dependent, as shown in Figure 3B. We chose two disparate lengths of double-stranded DNA to monitor, one of $40 \mathrm{bp}$ and another of $80 \mathrm{bp}$, and compared their 
respective rates of streptavidin displacement over time. As shown in Figure 3B, the steadystate of streptavidin displacement by RSCt is faster for the $40 \mathrm{bp}$ DNA than for the $80 \mathrm{bp}$ DNA. This is consistent with the 40 bp DNA having approximately $55 \%$ of binding sites lying within the DNA translocation processivity range of the 5' biotinylated end of the chain whereas on the 80 bp DNA substrate, only $\sim 22 \%$ fall within that range. RSCt bound to the 40 bp DNA will thus have a higher probability of being initially located within translocation distance of the biotin and consequently will more frequently come into contact with the streptavidin and thus have more opportunity to disrupt the bond than RSCt bound to the 80 bp DNA. Using this data across two lengths of DNA, we globally fit the data to a steadystate model of translocation and streptavidin displacement, shown in Equation 3. From this analysis we came up with a value for the rate of streptavidin displacement of $(7.16 \pm 0.05)$ $\times 10^{-3}$ displacements per second. All other rate constants in this analysis were constrained to values determined from previous analyses.

\section{Discussion}

Since DNA translocation by chromatin remodelers is required for these enzymes to reposition nucleosomes, a complete understanding of nucleosome repositioning by these enzymes requires a quantitative characterization of their mechanisms of DNA translocation. This includes not only a determination of the associated rate constants, but also an estimate of the efficiency at which these enzymes can couple the binding and hydrolysis of ATP to the physical work of DNA translocation. Here we have demonstrated a straightforward and generally applicable ensemble approach to obtaining both this information and an associated qualitative measurement of the forces exerted by the enzyme during DNA translocation.

Based upon the analysis of our results, we propose that RSCt must undergo an initiation process following its binding to DNA before becoming competent for DNA translocation. Furthermore, we propose a very weak coupling of ATP binding and hydrolysis to DNA translocation by RSCt. After considering the results of additional computer simulations, we propose that binding and possibly subsequent hydrolysis of ATP by RSCt can resort either in forward translocation or in a "paused" state of the enzyme. The presence of these periodic paused states further decreases processivity of DNA translocation by the enzyme. Finally, we also find that the molecular motor of RSCt has sufficient motive force to dissociate streptavidin from its biotin interaction during DNA translocation, indicating the complex's inherent capabilities for remodeling nucleosome structures in chromatin.

\section{Determination of Microscopic Translocation Parameters}

The time courses of double-stranded DNA translocation by RSCt are consistent with the presence of additional processes that both follow DNA binding and precede processive DNA translocation or that occur when RSCt has reached the end of the DNA. Further analysis of these time courses favored the former and therefore that corresponding model was used to determine estimates of the microscopic rate constants associated with DNA translocation by RSCt. It is worth noting, however, that estimates of macroscopic parameters are independent of the choice of model (data not shown) [43].

Through a global NLLS analysis of data collected using our fluorescence stopped-flow based DNA translocation assay using Scheme 1 (Equation 1) we have determined that RSCt translocates along double-stranded DNA through an ATP-dependent reaction characterized by a kinetic step size of $1.24 \pm 0.18 \mathrm{bp}$ and a macroscopic rate constant of $2.3 \pm 0.4 \mathrm{bp} / \mathrm{s}$. These results are consistent with previously published studies of double-stranded DNA translocation by the full RSC complex which have suggested a physical step size on the order of $1 \mathrm{nt}[13,22]$. Interestingly, our estimate of the processivity of DNA translocation, $\mathrm{P}$ $=0.92 \pm 0.01$, corresponds to a molecule of RSCt moving an average of $12 \pm 2$ steps before 
dissociation [40]. This is similar to but slightly smaller than what has been previously reported for the full RSC complex [23,50], suggesting that the other subunits of the full complex may also contribute to the DNA binding affinity of the enzyme.

The macroscopic translocation rate of DNA translocation by RSCt, $2.3 \pm 0.4 \mathrm{bp} / \mathrm{s}$, is similar to the macroscopic rate of single-stranded DNA translocation by the NS3h helicase from hepatitis $C$ virus (3 nt/s) [43], but much slower than the macroscopic rates of single-stranded DNA translocation by the UvrD (190 nt/s) [39], Rep (300 nt/s) [51] and T7 (132 nt/s) [52] helicases. This suggests a fundamental underlying structure-function difference between helicase superfamilies with SFII helicases (NS3h and RSC) translocating along single- or double-stranded DNA much more slowly than SFI (UvrD and Rep) or DNAB-like (T7) helicases. Of course, while these numbers are interesting to make general comparisons, it is difficult to draw distinctive conclusions from them as studies of these enzymes were performed under varying conditions.

\section{Computer Simulation Results}

We performed simulations in which hydrolysis of each ATP molecule resulted in forward motion of protein along the DNA, in backward motion along the DNA, or in a pause (or stall) in the motion of the protein [46]. Interestingly, the resulting translocation time courses could be modeled using Scheme 1 (Equation 1) even in the presence of non-uniform motions. We found that the inclusion of either backward motion or pausing events resulted in an increase in the estimate of the ATP coupling efficiency $(\mathrm{c} / \mathrm{m})$ and a decrease in the estimate of the macroscopic translocation rate $\left(m^{*} k_{t}\right)$. Although the estimate of the kinetic step size $(m)$ was increased in the presence of backward motion it was unaffected by random pausing. Since the value of $m$ determined from the analysis of the time courses of RSCt translocation along double-stranded DNA is $1.24 \pm 0.18$ bp (and thus is unlikely to be significantly over-estimated) we believe that the most likely explanation for the seemingly large value of $c / m$ observed for RSCt is that the enzyme undergoes random pausing during its translocation along the DNA. Interestingly, the occurrence of random pausing, especially when dissociation from the DNA substrate might occur during the paused state, would also be consistent with the relatively low processivity of DNA translocation that we observe for RSCt when compared to DNA translocation by helicases such as UvrD or NS3h, for which there was no indication of such non-uniformity in the translocation process. Furthermore, this would also be consistent with the observation that the ATP coupling stoichiometry for DNA translocation by UvrD (1 ATP/nt) and NS3h (0.5 ATP/nt) is lower than for RSCt (3 ATP/bp). Other remodelers in the ISWI family display low template commitment, releasing the substrate almost as fast as it is bound. It has been suggested SNF2 and hACF undergo several rounds of substrate sampling before a successful remodeling event takes place[53]. While the experiments with RSCt were not carried out on a nucleosome substrate, it is still worth mentioning that other remodeling proteins experience events that could 'pause' processive translocation.

It is worth noting that Sirinakis et al. report seeing backwards motion along the doublestranded DNA in their tethered StART molecule experiments [23]. However, it is difficult to determine if the backwards motion seen in those experiments is specific to the StART complex or a more general feature of the RSC motor; for example, since the StART complex is strongly tethered to the DNA initially, it is possible that backwards translocation may be enhanced when tension forces are applied.

\section{Relationship Between DNA Binding and Translocation}

Because DNA translocation is an ATP-dependent process, it involves repeating cycles of ATP binding, ATP hydrolysis, and product release [54]. These individual steps affect the 
apparent microscopic translocation properties as well as the macroscopic values that we determine from our analysis. It has been shown that RSCt binds DNA tightly in the absence of nucleotide but has a significant decrease in binding affinity in the presence of ADP, ATP or ATP-like analogues, on the order of 1000 fold [28]. Other helicases display similar characteristics, such as Rep, RepA, and RecQ [55-57]. In this system it would seem natural that RSCt would have a higher probability of dissociation during ATP-, or ADP-bound populations. However, if the subsequent hydrolysis event occurred on a short enough timescale, the impact of this reduction of binding affinity would not greatly affect the translocation characteristics of RSCt. It is nevertheless still possible that this slightly increased chance to dissociate would result in a lower processivity value in comparison to other translocases which do not show a similar allosteric regulation of their binding affinity. Indeed, the low processivity of DNA translocation by RSCt may result from the fact that its affinity for binding DNA is reduced in the presence of both ADP and ATP-analogs, regulation that is unique among previously reported studies of DNA binding by helicases. For example, the affinity of the Rep helicase for DNA binding is reduced in the presence of ATP, but unaffected by the presence of ADP[56], and the processivity of DNA translocation by the Rep helicase is $\sim 800 \mathrm{nt}[51]$. Furthermore, data also suggest an inverse relationship between the affinity of DNA binding and the macroscopic rate of DNA translocation. For example, the affinity of the Rep helicase for single-stranded DNA is (480 \pm 70$) \mathrm{nM}[56]$ with a corresponding macroscopic translocation rate of $(530 \pm 10) \mathrm{nt} / \mathrm{s}[51]$ whereas the affinity and macroscopic translocation rate for RSCt and double-stranded DNA are (99 \pm 5$) \mathrm{nM}$ [28] and $(2.3 \pm 0.1) \mathrm{bp} / \mathrm{s}$. A similar relationship has been observed for single-stranded nucleic acid translocation by the SFII helicase NS3h; the affinity and macroscopic translocation rate for oligo(dT) are $139 \pm 6 \mathrm{nM}$ and $3.1 \pm 0.3 \mathrm{nt} / \mathrm{s}$, respectively, and for oligo(dU) are $530 \pm 60$ $\mathrm{nM}$ and $34.2 \mathrm{nt} / \mathrm{s}$ [43], respectively. Direct comparisons between translocases are naturally problematic because of differences in solution conditions and assays, but these trends are nevertheless noteworthy.

\section{RSCt Utilizes Several ATP Molecules per Translocative Step}

It is important to remember that the kinetic step size determined for double-stranded DNA translocation by RSCt is a measure of the average number of nucleotides translocated between two repeated rate-limiting steps in Scheme 1. Thus, both $m$ and $k_{t}$ may not reflect the step size or rate constant for the physical movement of the enzyme, but rather the step that is rate-limiting, a protein conformational change, the release of ADP or inorganic phosphate, etc. $[38,39]$. Further insight into the physical mechanism of DNA translocation by RSCt can be determined from an analysis of the DNA-stimulated ATPase activity of the enzyme [43]. Indeed, through a global analysis of the dependence on DNA length of the maximum DNA-stimulated ATPase rate (i.e., the rate obtained under saturating DNA concentrations) we determined that RSCt hydrolyzes ( $3.77 \pm 0.02)$ ATP per second per $\mathrm{RSCt}$ molecule per rate-limiting step. This corresponds to RSCt hydrolyzing 3.0 ATP per bp translocated, which is less efficient than the previously reported ATP coupling stoichiometries for single-standed DNA translocation by other helicases [43,52]. Furthermore, this result suggests that a large amount of futile ATP hydrolysis (i.e., hydrolysis not connected with the translocation of RSCt along the DNA) occurs during the translocation reaction. This may correspond to hydrolysis occurring during the additional kinetic process observed for the kinetic mechanism of DNA translocation. It is difficult to consider how these sorts of pausing, futile occurrences would affect the results of our modeled pausing events. It could be the case that it is not an individual event that would directly relate to the modeled pausing step but a collection of cases whose sum would be the value found in our results. Over the course of an average of 12 steps in a round of translocation, any pauses taken, involving ATP-binding, hydrolysis, movement, and DNA rebinding, would show up in our data fitting as a single microscopic parameter. 
Nevertheless, without direct experimental results on the rapidity of ATP hydrolysis and release during translocation, this remains only a conjecture in regards to our results. It is still not possible to determine if the modeled pausing event is a single, long event, or the accumulation of multiple fast steps in each round of translocation.

Another explanation for the poor coupling stoichiometry and the large amount of futile hydrolysis would be if RSCt experienced non-uniform motion during its translocation along the DNA; possible examples of non-uniform motion would be backward motion or random pausing [36]. Indeed, based upon results of computer simulated DNA translocation time courses we believe that RSCt undergoes frequent random pausing during its translocation along the DNA. During these pauses RSCt can dissociate from the DNA and/or undergo rounds of futile ATP hydrolysis. As discussed above, a model for DNA translocation by RSCt which includes ATP-dependent random pausing would also be consistent with the relatively low processivity of DNA translocation by RSCt since the enzyme can dissociate from the paused state. Thus, together our kinetic data favor a model in which the binding and/or hydrolysis of ATP is associated either with forward motion or pausing. This, in turn, argues in favor the pausing being a stalled or failed translocation of the enzyme along the DNA.

As determined above, the maximal rate of DNA-stimulated ATPase for RSCt is $(3.77 \pm$ 0.02) ATP per RSCt per second. In our DNA experiments with $50 \mathrm{nM} \mathrm{RSCt}$ and $1 \mathrm{mM}$ ATP approximately $9 \%$ of the ATP would have been consumed during the first 8 minutes of the reaction and approximately $14 \%$ will have been consumed over the entire experiment. Since a linear fit was consistent with our ATPase time-courses (Figure X), this suggests that the kinetics of ATP binding are not rate-limiting for the DNA-stimulated ATPase of RSCt. Thus, this decrease in ATP concentration appears to not significantly affect our results; we nevertheless wished to determine how this decrease in ATP concentration would affect our estimate of $k_{c a t}$. Based upon model equations derived in Fischer et al.[38] which model the apparent rate constant of translocation, $k_{t}$, in terms of the concentration of ATP, the equation

$$
k_{t}=\frac{K_{T}[A T P]}{1+K_{T}[A T P]} k_{f}
$$

shows the ATP concentration dependence of $k_{t}$. The variable $K_{T}$ is the equilibrium binding constant, which is a ratio of the ATP-binding rate constant $k_{1}$ and the ATP dissociation rate constant $k_{-}$, and the variable $k_{f}$ is rate constant governing processive forward translocation after nucleotide binding. The equation makes the assumption that the dissociation rate constant is much faster than the forward rate of translocation $\left(k_{-1}>>k_{f}\right)$. From Malik et al. [28], we know that the equilibrium constant for protein/DNA interaction with ATP is $9 \times$ $10^{3} \mathrm{M}^{-1}$ which is also equal to the ration $k_{1} / k_{-1}$. From previously published estimates of the association rate constant $k_{1}$ being on the order of $10^{7} \mathrm{M}^{-1} \mathrm{~s}^{-1}$ [58], implying a dissociation rate, $k_{-1}$, of $10^{3} \mathrm{~s}^{-1}$. From the results of our global analysis, we know that processive translocation occurs for RSCt at a rate of $\sim 3 \mathrm{~s}^{-1}$ which puts us well within the regime $k_{-1}$ >> $k f$. After affirming this underlying assumption, we continued with the analysis of the above equation. Considering a reduction of $14 \%$ from the initial $1 \mathrm{mM}$ ATP concentration, the forward translocation constant $k_{t}$ only loses $1.6 \%$ of its value. Due to this very small drop in $k_{t}$, the processivity defined in Equation 5 remains within $0.5 \%$ of its original value. Finally, since the equation for $k_{c a t}$ (Equation 4 ) is heavily dependent on $k_{t}$ and $P$, this reduction of overall ATP concentration gives a negligible change in the value of $k_{c a t}$.

\section{RSCt Is a Relatively Slow and Short Processive Translocase}

From our analyses we determined the processivity of double-stranded DNA translocation by RSCt to be $0.92 \pm 0.01$ which corresponds to a low average number of $14.3 \pm 0.6$ basepairs 
traveled by RSCt before dissociation. This estimate is similar to a previously reported value of $20 \pm 1$ bp by Fischer et al [40] for the full RSC complex [19,30]. The small difference can most likely be attributed to the full complex of RSC having a different interaction with its double-stranded substrate than the smaller RSC trimer. In comparison to other translocase proteins, RSCt is a relatively poor translocase. The HCV helicase NS3h has been shown to have a processivity value between 0.993 and 0.98 corresponding to an average of 230 basepairs traveled before dissociation $[31,43]$. The E. coli helicase UvrD has an even higher value of 0.997 and $2400 \mathrm{bp}$ covered [39].

The kinetic step size that we determined from our analyses is $1.24 \pm 0.18$ base pair which is in agreement with previous determinations where, during experiments measuring the capability of RSC to displace triple-helix forming oligonucleotides, a single base pair gap in the tracking strand was sufficient to obstruct the displacement activity $[13,19,22]$.

\section{RSCt Is Capable of Exerting Large Forces during DNA Translocation}

The fact that RSCt can dislocate streptavidin from a biotin link is significant. It shows that the motor domain shows sufficient strength to remove a bond which has an affinity on the order of $10^{-14} \mathrm{M}$. Furthermore, this can provide an estimate of the power available for the protein's necessary task of chromatin remodeling. A protein's capability of disrupting this strong bond points to similarities in the forces required for dislocating the linkages between a histone octamer and its associated DNA. Although RSCt is clearly capable of displacing streptavidin in our assays, the reaction is extremely slow, happening every 2 minutes on average. A possible scenario for this situation would be that when RSCt translocates to the end of the DNA strand and comes into contact with the biotin-streptavidin linkage, it primarily dissociates and displaces the streptavidin with a much low probability. Sirinakis et al. provides an upper-bound estimate of the forces involved in single-molecule DNAtranslocation of $30 \mathrm{pN}$ [23]. Considering that nucleosomal structure has been shown to be disrupted at a mechanical force of $23 \mathrm{pN}$ [59], these results lend further evidence that the DNA-RSCt interaction strength is large enough to displace the contacts at even highstrength binding locations such as the nucleosomal dyad [60].

\section{Comparison to Single Molecule Studies}

A similar minimalist RSC construct was utilized by Sirinakis et al. in a single molecule DNA translocation assay [23]. In those experiments, however, the STH1 component of the trimeric complex was modified to include a fusion to the site specific DNA binding protein TetR [23]. Although the results of that study do not allow for a determination of the kinetic mechanism of DNA translocation and associated microscopic parameters the authors did provide an estimate of the macroscopic kinetic parameters which are noticeably larger than those we present here. Sirinakis et al. report that RSCt translocates an average of $\sim 35$ bp per round of translocation [23], which is double our estimate of $14.3 \pm 0.6 \mathrm{bp}$. Interestingly, in studies of the DNA translocation activity of full-length RSC larger estimates of kinetic parameters were observed for single-molecule studies than for ensemble studies $[17,40,50]$. In order to resolve this discrepancy it was proposed that RSC may have two distinct processive modes [40]; a common, less processive mode that is not readily observable in single-molecule experiments and provides the basis for ensemble method results, and a more rare, highly processive mode, which dominates data recorded in single-molecule experiments. In ensemble experiments this latter mode would not have a large effect on the averages found due to the infrequent nature of the particular mode. Conversely, in singlemolecule experiments it would play a significant role owing to the limited resolution of the associated instruments. A typical minimum loop detection size limit of $10 \mathrm{bp}$ in singlemolecule experiments would necessarily exclude the common mode from being detected, thereby increasing the apparent average distance translocated. However, ensemble 
experiments sample the modalities in their natural frequencies, providing more complete averaging bases. Coincident with a loop size bias inherent within the detection resolution of the instrument, the reported average distance traveled of 35 bp may also be affected by numerous extremely large measurements, several orders of magnitude larger than the stochastic average, such as the single instance of $1500 \mathrm{bp}$ translocated [23]. It is also possible that the high affinity of the TetR tag on the StART complex for the DNA itself is also artificially increasing the processivity of translocation and thereby making direct comparisons between the two sets of experiments problematic. Other dissimilarities become apparent in the comparisons between RSCt and StART which could potentially be explained by the difference in structure between the two proteins. In Sirinikis et al. when discussing the properties of their StART complex, it is mentioned that it has the same DNA-dependent ATPase activity as the full RSC protein which corresponds to $\sim 5 \mathrm{ATP} / \mathrm{sec}$ [23]. Combined with their reported translocation speed of $\sim 25 \mathrm{bp} / \mathrm{sec}$, this would imply a rate of $5 \mathrm{bp} / \mathrm{ATP}$, which seems inconsistent with the estimate of $2 \mathrm{bp} / \mathrm{step}$ for a kinetic step size. However, there is good agreement between the high-force-exerting capabilities of the core RSC complex. While we have shown that RSCt has extreme motile forces in translocation by showing biotin-streptavidin displacement during translocation, the single-molecule assay points to forces generated in their experiments of up to $30 \mathrm{pN}$. Both of these results suggest that during translocation and nucleosome repositioning, large forces may be required to complete the complex's role in the nucleus.

\section{Acknowledgments}

The authors would like to thank Gada Al-Ani, Koan Briggs, and Micheal Conner for helpful discussion concerning the results and comments on the manuscript. This work was supported by National Institutes of Health Grant P20 RR017708 and by the University of Kansas General Research Fund.

\section{Abbreviations}

$\begin{array}{ll}\text { RSC } & \text { Remodel the Structure of Chromatin } \\ \text { RSCt } & \text { Remodel the Structure of Chromatin trimer (used in this study) } \\ \text { NLLS } & \text { non-linear least squares } \\ \text { bp } & \text { basepair }\end{array}$

\section{Bibliography}

1. Ehrenhofer-Murray AE. Chromatin dynamics at DNA replication, transcription and repair. Eur. J. Biochem. / FEBS. 2004; 271:2335-2349.

2. Elgin SCR, Grewal SIS. Heterochromatin: silence is golden. Curr. Biol.: CB. 2003; 13:R895-R898.

3. Luger K, Mäder AW, Richmond RK, Sargent DF, Richmond TJ. Crystal structure of the nucleosome core particle at 2.8 A resolution. Nat. 1997; 389:251-260.

4. Richmond TJ, Davey CA. The structure of DNA in the nucleosome core. Nat. 2003; 423:145-150.

5. Fuino L, Bali P, Wittmann S, Donapaty S, Guo F, Yamaguchi H, et al. Histone deacetylase inhibitor LAQ824 down-regulates Her-2 and sensitizes human breast cancer cells to trastuzumab, taxotere, gemcitabine, and epothilone B. Mol. Cancer Ther. 2003; 2:971-984. [PubMed: 14578462]

6. Jenuwein T, Allis CD. Translating the histone code. Science (New York, N.Y.). 2001; 293:10741080.

7. Bowman GD. Mechanisms of ATP-dependent nucleosome sliding. Curr. Opin. Struct. Biol. 2010; 20:73-81. [PubMed: 20060707]

8. Saha A, Wittmeyer J, Cairns BR. Chromatin remodelling: the industrial revolution of DNA around histones. Nat. Rev. Mol. Cell Biol. 2006; 7:437-447. [PubMed: 16723979] 
9. Becker PB, Hörz W. ATP-dependent nucleosome remodeling. Annu. Rev. Biochem. 2002; 71:247273. [PubMed: 12045097]

10. Sala A, Corona DFV. Poly-ADP-ribose (PAR) as an epigenetic flag. Epigenetics: Official Journal of the DNA Methylation Society. 2009; 4:287-290. [PubMed: 19633412]

11. Sala A, La Rocca G, Burgio G, Kotova E, Di Gesù D, Collesano M, et al. The nucleosomeremodeling ATPase ISWI is regulated by poly-ADP-ribosylation. PLoS Biol. 2008; 6:e252. [PubMed: 18922045]

12. Clapier CR, Cairns BR. The biology of chromatin remodeling complexes. Ann. Rev. Biochem. 2009; 78:273-304. [PubMed: 19355820]

13. Saha A, Wittmeyer J, Cairns BR. Chromatin remodeling through directional DNA translocation from an internal nucleosomal site. Nat. Struct. Mol. Biol. 2005; 12:747-755. [PubMed: 16086025]

14. Eberharter A, Becker PB. ATP-dependent nucleosome remodelling: factors and functions. J. Cell Sci. 2004; 117:3707-3711. [PubMed: 15286171]

15. Längst G, Becker PB. ISWI Induces Nucleosome Sliding on Nicked DNA. Mol. Cell. 2001; 8:1085-1092. [PubMed: 11741543]

16. Leschziner AE, Saha A, Wittmeyer J, Zhang Y, Bustamante C, Cairns BR, et al. Conformational flexibility in the chromatin remodeler RSC observed by electron microscopy and the orthogonal tilt reconstruction method. Proc. Natl. Acad. Sci. U. S. A. 2007; 104:4913-4918. [PubMed: 17360331]

17. Zhang Y, Smith CL, Saha A, Grill SW, Mihardja S, Smith SB, et al. DNA translocation and loop formation mechanism of chromatin remodeling by SWI/SNF and RSC. Mol. Cell. 2006; 24:559568. [PubMed: 17188033]

18. Fitzgerald DJ, DeLuca C, Berger I, Gaillard H, Sigrist R, Schimmele K, et al. Reaction cycle of the yeast Isw2 chromatin remodeling complex. EMBO J. 2004; 23:3836-3843. [PubMed: 15359274]

19. Cairns BR, Lorch Y, Li Y, Zhang M, Lacomis L, Erdjument-Bromage H, et al. RSC, an Essential, Abundant Chromatin-Remodeling Complex. Cell. 1996; 87:1249-1260. [PubMed: 8980231]

20. Lorch Y, Zhang M, Kornberg RD. RSC unravels the nucleosome. Mol. Cell. 2001; 7:89-95. [PubMed: 11172714]

21. Lorch Y, Zhang M, Kornberg RD. Histone Octamer Transfer by a Chromatin-Remodeling Complex. Cell. 1999; 96:389-392. [PubMed: 10025404]

22. Saha A, Wittmeyer J, Cairns BR. Chromatin remodeling by RSC involves ATP-dependent DNA translocation. Genes Dev. 2002; 16:2120-2134. [PubMed: 12183366]

23. Sirinakis G, Clapier CR, Gao Y, Viswanathan R, Cairns BR, Zhang Y. The RSC chromatin remodelling ATPase translocates DNA with high force and small step size. EMBO J. 2011

24. Lorch Y, Cairns BR, Zhang M, Kornberg RD. Activated RSC-Nucleosome Complex and Persistently Altered Form of the Nucleosome. Cell. 1998; 94:29-34. [PubMed: 9674424]

25. Lorch Y, Maier-Davis B, Kornberg RD. Mechanism of chromatin remodeling. Proceedings of the National Academy of Sciences of the United States of America. 2010; 107:3458-3462. [PubMed: 20142505]

26. Shukla MS, Syed SH, Montel F, Faivre-Moskalenko C, Bednar J, Travers A, et al. Remosomes: RSC generated non-mobilized particles with approximately 180 bp DNA loosely associated with the histone octamer. Proc. Natl. Acad. Sci. U. S. A. 2010; 107:1936-1941. [PubMed: 20080697]

27. Zofall M, Persinger J, Kassabov SR, Bartholomew B. Chromatin remodeling by ISW2 and SWI/ SNF requires DNA translocation inside the nucleosome. Nat. Struct. Mol. Biol. 2006; 13:339-346. [PubMed: 16518397]

28. Malik S, Rich E, Viswanathan R, Cairns BR, Fischer CJ. Allosteric interactions of DNA and nucleotides with S. cerevisiae RSC. Biochemistry. 2011; 50:7881-7890. [PubMed: 21834590]

29. Cairns BR, Erdjument-Bromage H, Tempst P, Winston F, Kornberg RD. Two actin-related proteins are shared functional components of the chromatin-remodeling complexes RSC and SWI/ SNF. Mol. Cell. 1998; 2:639-651. [PubMed: 9844636]

30. Du J, Nasir I, Benton BK, Kladde MP, Laurent BC. Sth1p, a Saccharomyces cerevisiae Snf2p/ Swi2p homolog, is an essential ATPase in RSC and differs from Snf/Swi in its interactions with histones and chromatin-associated proteins. Genetics. 1998; 150:987-1005. [PubMed: 9799253] 
31. Matlock DL, Yeruva L, Byrd AK, Mackintosh SG, Langston C, Brown C, et al. Investigation of translocation, DNA unwinding, and protein displacement by NS3h, the helicase domain from the hepatitis C virus helicase. Biochemistry. 2010; 49:2097-2109. [PubMed: 20108974]

32. Lohman TM, Bjornson KP. Mechanisms of helicase-catalyzed DNA unwinding. Annu. Rev. Biochem. 1996; 65:169-214. [PubMed: 8811178]

33. Lucius AL, Maluf NK, Fischer CJ, Lohman TM. General methods for analysis of sequential "nstep" kinetic mechanisms: application to single turnover kinetics of helicase-catalyzed DNA unwinding. Biophys. J. 2003; 85:2224-2239. [PubMed: 14507688]

34. Morris PD, Byrd AK, Tackett AJ, Cameron CE, Tanega P, Ott R, et al. Hepatitis C virus NS3 and simian virus $40 \mathrm{~T}$ antigen helicases displace streptavidin from 5'-biotinylated oligonucleotides but not from 3'-biotinylated oligonucleotides: evidence for directional bias in translocation on singlestranded DNA. Biochemistry. 2002; 41:2372-2378. [PubMed: 11841230]

35. Williams DJ, Hall KB. Monte Carlo applications to thermal and chemical denaturation experiments of nucleic acids and proteins. Methods Enzymol. 2000; 321:330-352. [PubMed: 10909065]

36. Tomko EJ, Fischer CJ, Lohman TM. Ensemble methods for monitoring enzyme translocation along single stranded nucleic acids. Methods (San Diego, Calif.). 2010

37. Fischer CJ, Wooten L, Tomko EJ, Lohman TM. Kinetics of motor protein translocation on singlestranded DNA. Methods Mol. Biol. (Clifton, N.J.). 2010; 587:45-56.

38. Fischer CJ, Lohman TM. ATP-dependent translocation of proteins along single-stranded DNA: models and methods of analysis of pre-steady state kinetics. J. Mol. Biol. 2004; 344:1265-1286. [PubMed: 15561143]

39. Fischer CJ, Maluf NK, Lohman TM. Mechanism of ATP-dependent translocation of E. coli UvrD monomers along single-stranded DNA. J. Mol. Biol. 2004; 344:1287-1309. [PubMed: 15561144]

40. Fischer CJ, Saha A, Cairns BR. Kinetic model for the ATP-dependent translocation of Saccharomyces cerevisiae RSC along double-stranded DNA. Biochemistry. 2007; 46:1241612426. [PubMed: 17918861]

41. Fischer CJ, Yamada K, Fitzgerald DJ. Kinetic mechanism for single-stranded DNA binding and translocation by Saccharomyces cerevisiae Isw2. Biochemistry. 2009; 48:2960-2968. [PubMed: 19203228]

42. Tomko EJ, Fischer CJ, Niedziela-Majka A, Lohman TM. A nonuniform stepping mechanism for E. coli UvrD monomer translocation along single-stranded DNA. Mol. Cell. 2007; 26:335-347. [PubMed: 17499041]

43. Khaki AR, Field C, Malik S, Niedziela-Majka A, Leavitt SA, Wang R, et al. The macroscopic rate of nucleic acid translocation by hepatitis C virus helicase NS3h is dependent on both sugar and base moieties. J. Mol. Biol. 2010; 400:354-378. [PubMed: 20451531]

44. von Hippel PH, Delagoutte E. A general model for nucleic acid helicases and their"coupling" within macromolecular machines. Cell. 2001; 104:177-190. [PubMed: 11207360]

45. McClure WR, Chow Y. The kinetics and processivity of nucleic acid polymerases. Methods Enzymol. 1980; 64:277-297. [PubMed: 6990186]

46. Fischer CJ, Wooten L, Tomko EJ, Eastlund A, Lohman TM. Effects of Non-uniform motion. Static and Dynamic Disorder on the Kinetic Parameters obtained from Ensemble Studies of Nucleic Acid Translocases and Helicases, (n.d.).

47. Zhang W, Bond JP, Anderson CF, Lohman TM, Record MT. Large electrostatic differences in the binding thermodynamics of a cationic peptide to oligomeric and polymeric DNA. Proc. Natl. Acad. Sci. U. S. A. 1996; 93:2511-2516. [PubMed: 8637905]

48. Zhang W, Ni H, Capp MW, Anderson CF, Lohman TM, Record MT. The importance of coulombic end effects: experimental characterization of the effects of oligonucleotide flanking charges on the strength and salt dependence of oligocation (L8+) binding to single-stranded DNA oligomers. Biophys. J. 1999; 76:1008-1017. [PubMed: 9916032]

49. Green NM. Avidin. Adv. Protein Chem. 1975; 29:85-133. [PubMed: 237414]

50. Lia G, Praly E, Ferreira H, Stockdale C, Tse-Dinh YC, Dunlap D, et al. Direct observation of DNA distortion by the RSC complex. Mol. Cell. 2006; 21:417-425. [PubMed: 16455496] 
51. Brendza KM, Cheng W, Fischer CJ, Chesnik MA, Niedziela-Majka A, Lohman TM. Autoinhibition of Escherichia coli Rep monomer helicase activity by its 2B subdomain. Proc. Natl. Acad. Sci. U. S. A. 2005; 102:10076-10081. [PubMed: 16009938]

52. Kim D-E, Narayan M, Patel SS. T7 DNA helicase: a molecular motor that processively and unidirectionally translocates along single-stranded DNA. J. Mol. Biol. 2002; 321:807-819. [PubMed: 12206763]

53. He X, Fan H-Y, Narlikar GJ, Kingston RE. Human ACF1 alters the remodeling strategy of SNF2h. J Biol. Chem. 2006; 281:28636-28647. [PubMed: 16877760]

54. Levin MK, Gurjar MM, Patel SS. ATP binding modulates the nucleic acid affinity of hepatitis C virus helicase. J. Biol. Chem. 2003; 278:23311-23316. [PubMed: 12660239]

55. Andreeva IE, Roychowdhury A, Szymanski MR, Jezewska MJ, Bujalowski W. Mechanisms of interactions of the nucleotide cofactor with the RepA protein of plasmid RSF1010. Binding dynamics studied using the fluorescence stopped-flow method. Biochemistry. 2009; 48:1062010636. [PubMed: 19747005]

56. Wong I, Lohman TM. Allosteric effects of nucleotide cofactors on Escherichia coli Rep helicaseDNA binding. Science (New York, N.Y.). 1992; 256:350-355.

57. Dou S-X, Wang P-Y, Xu HQ, Xi XG. The DNA binding properties of the Escherichia coli RecQ helicase. J. Biol. Chem. 2004; 279:6354-6363. [PubMed: 14665634]

58. Hsieh J, Moore KJ, Lohman TM. A two-site kinetic mechanism for ATP binding and hydrolysis by E. coli Rep helicase dimer bound to a single-stranded oligodeoxynucleotide. J. Mol. Biol. 1999; 288:255-274. [PubMed: 10329141]

59. Brower-Toland BD, Smith CL, Yeh RC, Lis JT, Peterson CL, Wang MD. Mechanical disruption of individual nucleosomes reveals a reversible multistage release of DNA. Proc. Natl. Acad. Sci. U. S. A. 2002; 99:1960-1965. [PubMed: 11854495]

60. Luger K, Richmond TJ. DNA binding within the nucleosome core. Curr. Opin. Struct. Biol. 1998; 8:33-40. [PubMed: 9519294] 


\section{Highlights}

We determine microscopic rate constants for processive RSCt translocation We report values for ATP coupling stoichiometries

$\mathrm{RSCt}$ is an inefficient motor, using several ATP per forward step

RSCt is capable of disrupting the streptavidin-biotin linkage 


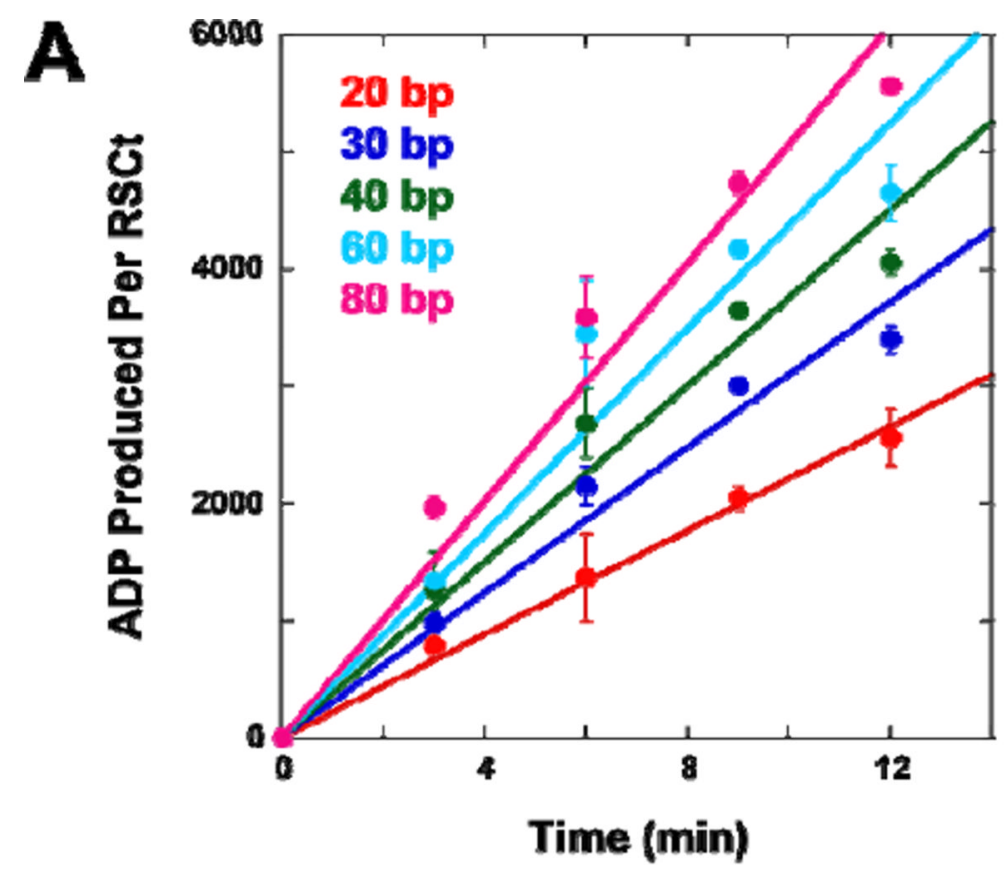

B

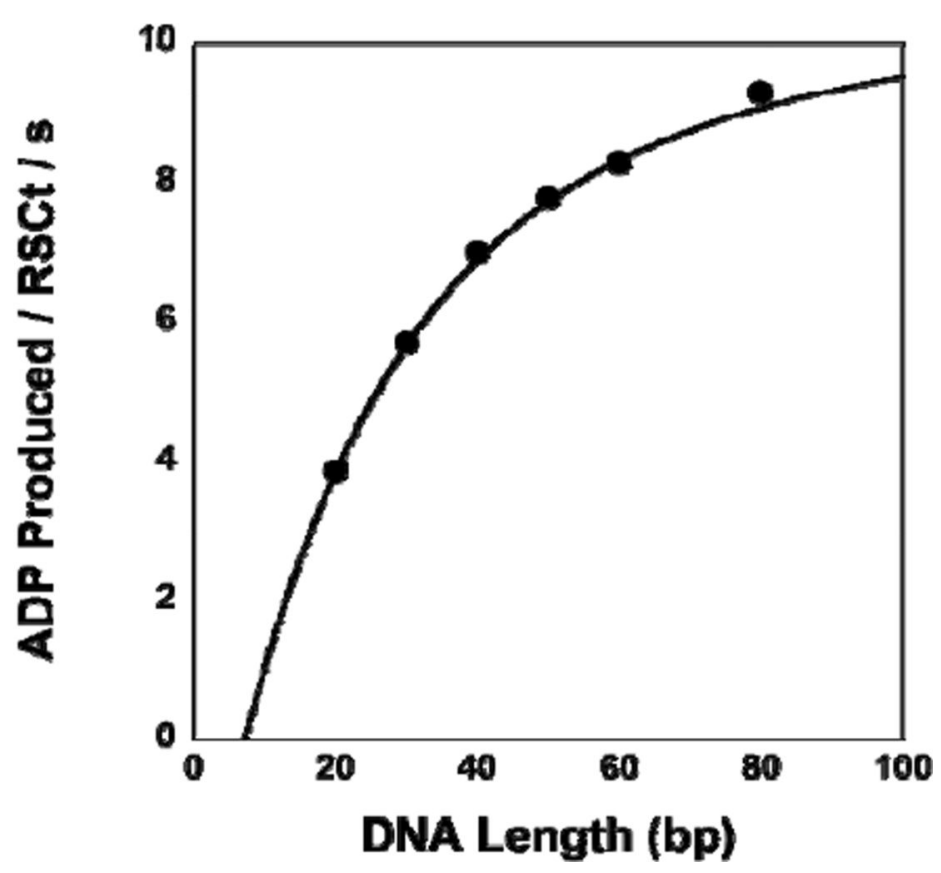

Figure 1.

RSCt Is A DNA Translocase. A) Time course of ADP production for RSCt translocating along DNA of varying lengths. The solid lines are linear fits of the time courses used to determine the value of $\mathrm{k}_{\mathrm{cat}}$ for each length. B) Dependence of the $\mathrm{k}_{\mathrm{cat}}$ of the DNA stimulated ATPase activity of RSCt on DNA length. The solid line in the figure is a fit of the data using Equation 4. 

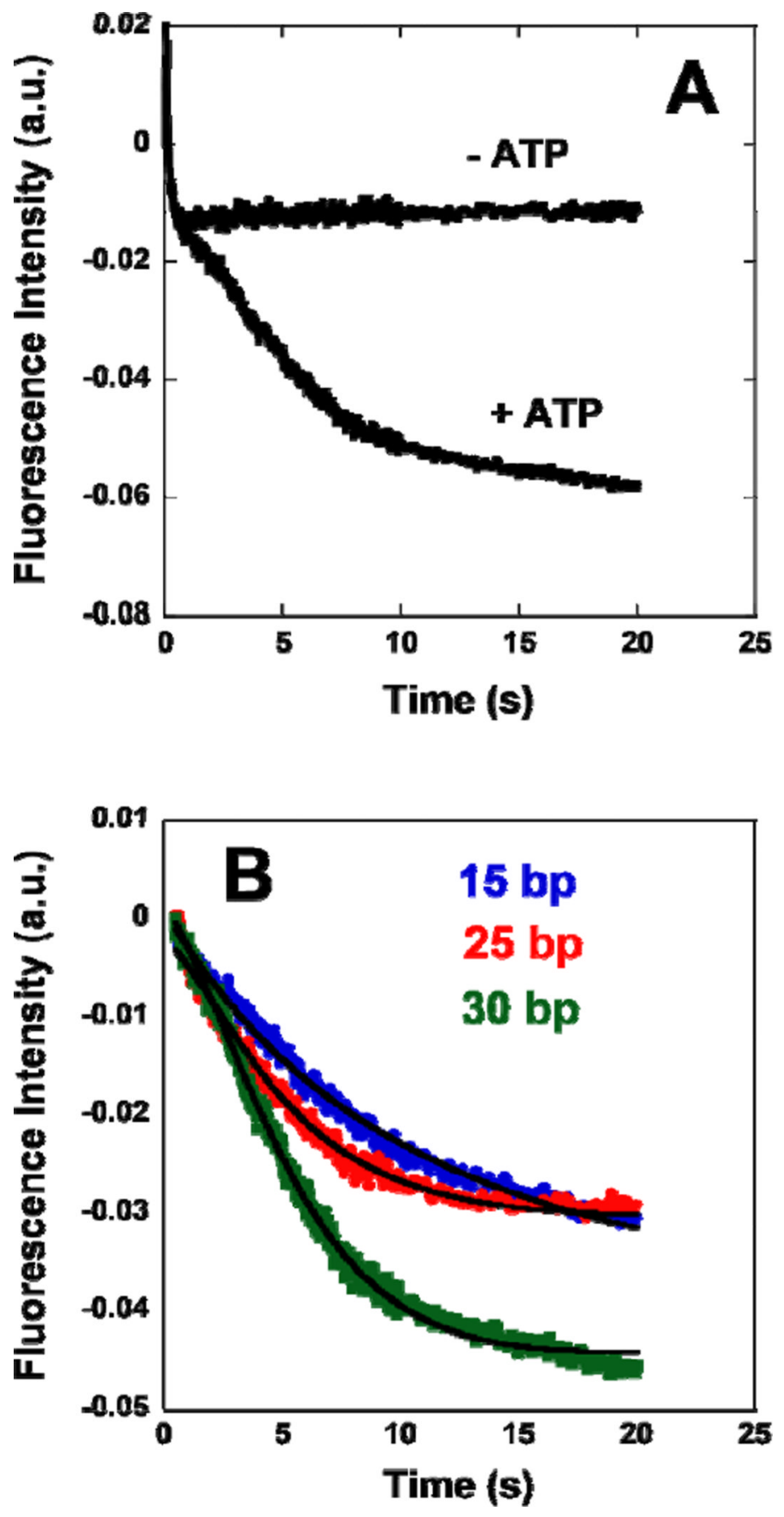

Figure 2.

Monitoring DNA Translocation By RSCt Using A Fluorescence Stopped-Flow Assay. A) ATP $+/-$ Controls. A stopped-flow chart showing the spectrographic signal involved in binding and translocation in the presence of ATP as well as binding with no translocation in the absence of ATP. These results show that ATP is a required component in translocation stopped-flow experiments. Without the presence of ATP, we see no change in fluorescence signal indicative of molecular translocation. Only upon the addition of ATP to the mixing solution do we see any signal change characteristic of translocation by RSC. In very short time-courses $(>0.5 \mathrm{~s})$, we detect a signal change that is present in both -ATP and +ATP experiments. Past this timescale is when we are able to determine defining characteristics 
between the two sets of data. This data set was taken using $25 \mathrm{bp}$ double-stranded fluorescein-labeled DNA. B) Time courses for translocation of RSCt along 15 (red), 25 (blue), and 30 (green) bp DNA substrates. The data set for each DNA length is an average of 25 independent experiments. The black lines show the results generated by a global NLLS fit of the data using Equation 1 which describes an initiation step model with the DNA length as a defining parameter. 


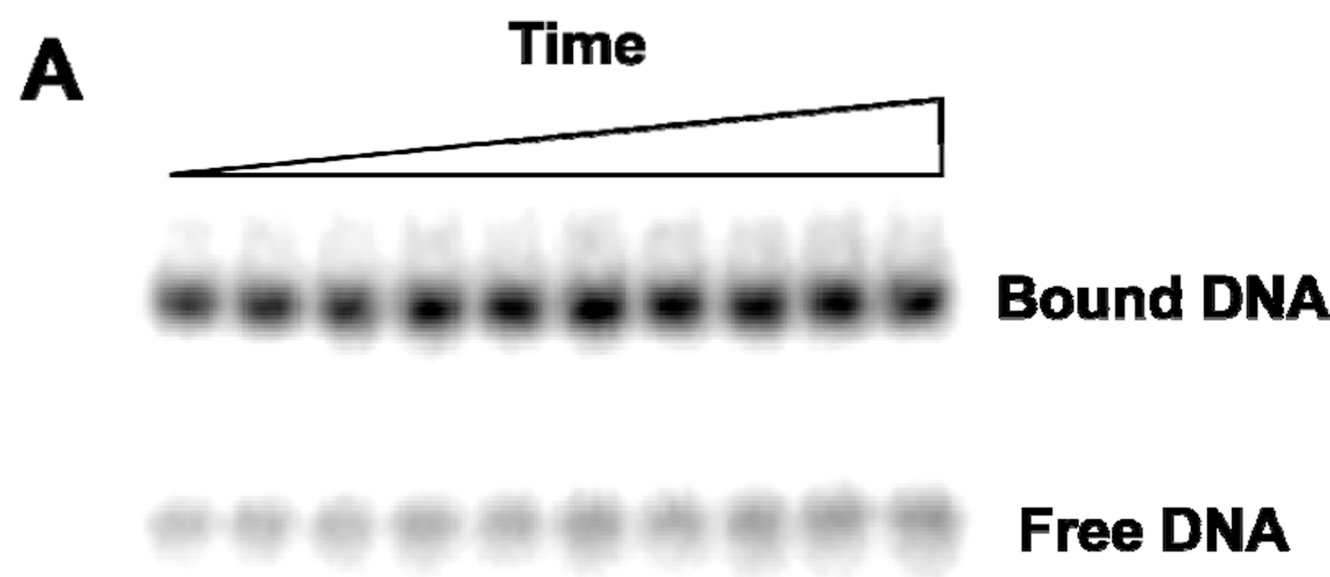

B

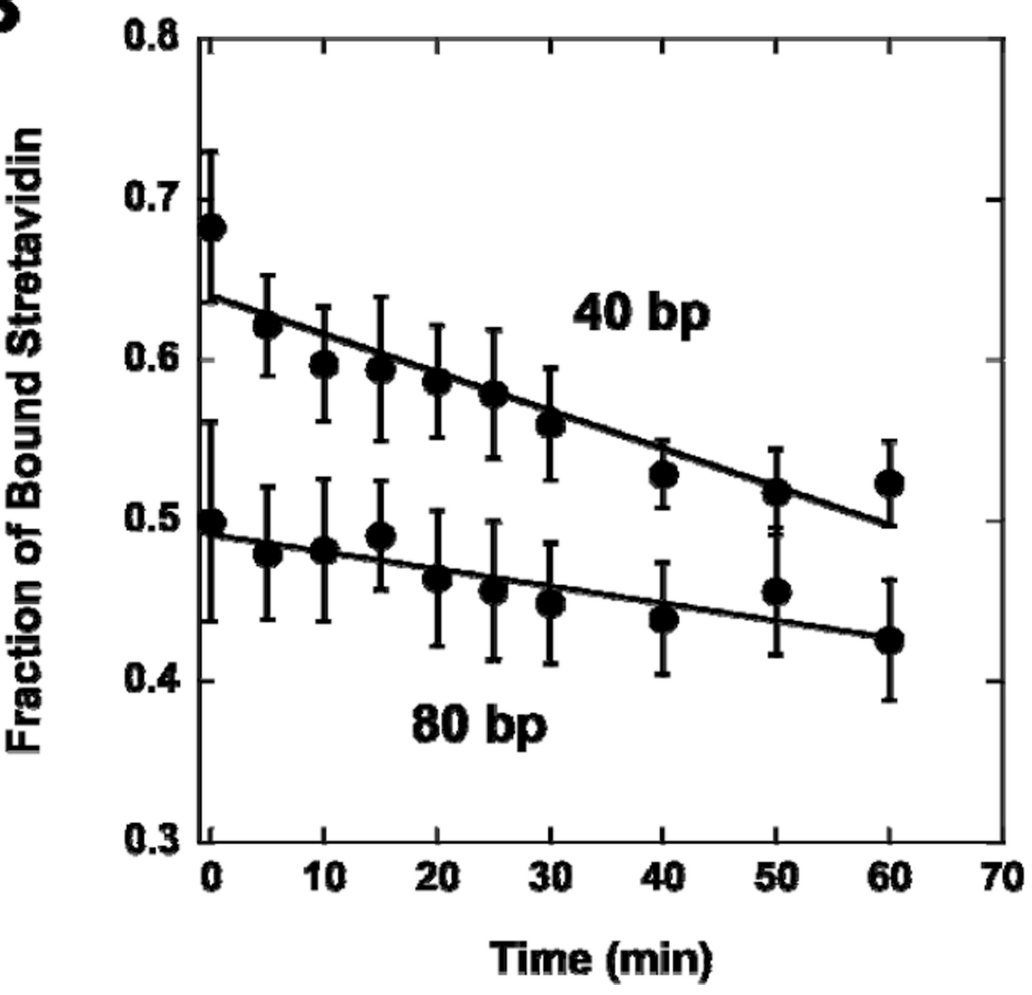

Figure 3.

Streptavidin Displacement Due To RSCt. A) Native gel example showing streptavidin displacement due to RSC. At increasing time intervals (increasing lane numbers), we see larger signal from free DNA indicating streptavidin displacement from the DNA-biotin linkage. This control experiment was conducted using 40bp DNA substrate at the listed concentrations of streptavidin, RSCt, and DNA as described in Materials and Methods. B) Streptavidin displacement versus time along 40 and 80 bp DNA substrates. The data sets are averages of three runs and the standard deviation is shown. The solid lines are linear fits to the data weighted by their respective errors. Note that RSCt displaces more overall streptavidin on the $40 \mathrm{bp}$ substrate than on the $80 \mathrm{bp}$ substrate. 


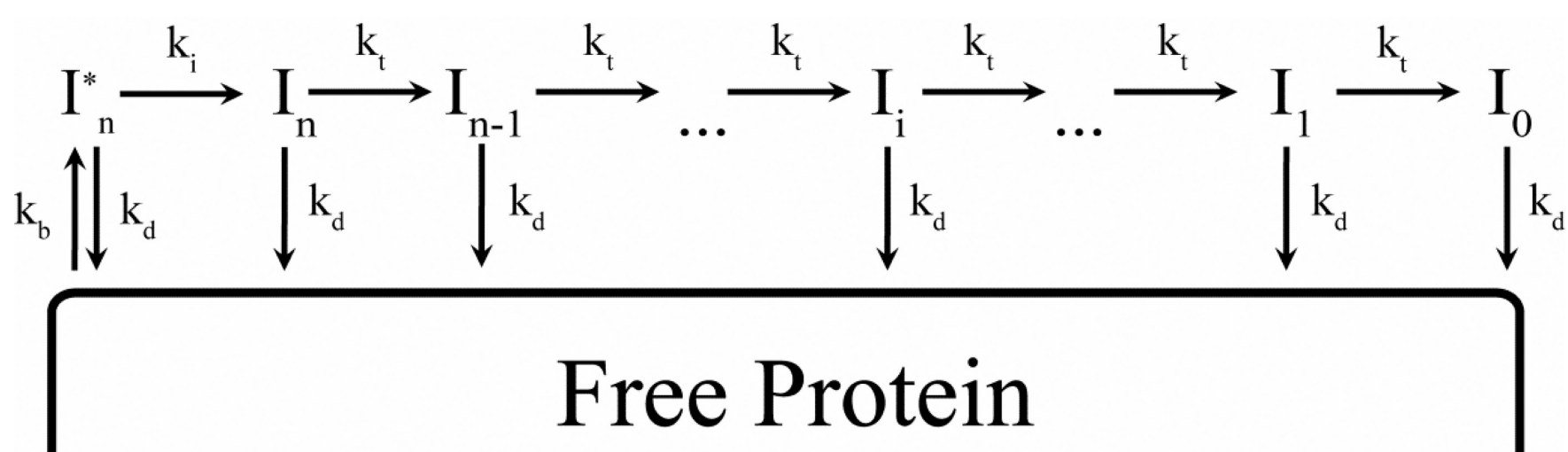

Scheme 1.

Paused Step Model. Before initiating translocation, the protein binds with rate constant $k_{b}$ to a random location along the DNA substrate and begins the process in state $\mathrm{I}_{\mathrm{n}}{ }^{*}$. In this state the protein can either dissociate with rate constant $k_{d}$ or go through some form of conformational or energetic change that precedes translocation and is governed by rate constant $k_{i}$. Upon completing any slow-step process that could be concealed in this initiative activity, the protein is then in state $I_{n}$ and prepared for processive translocation. Any further translocation is governed by the rate constant $k_{t}$ and at each available state $\mathrm{I}_{\mathrm{i}}$ can either proceed at a rate $k_{t}$ or dissociate with a rate $k_{d}$. 


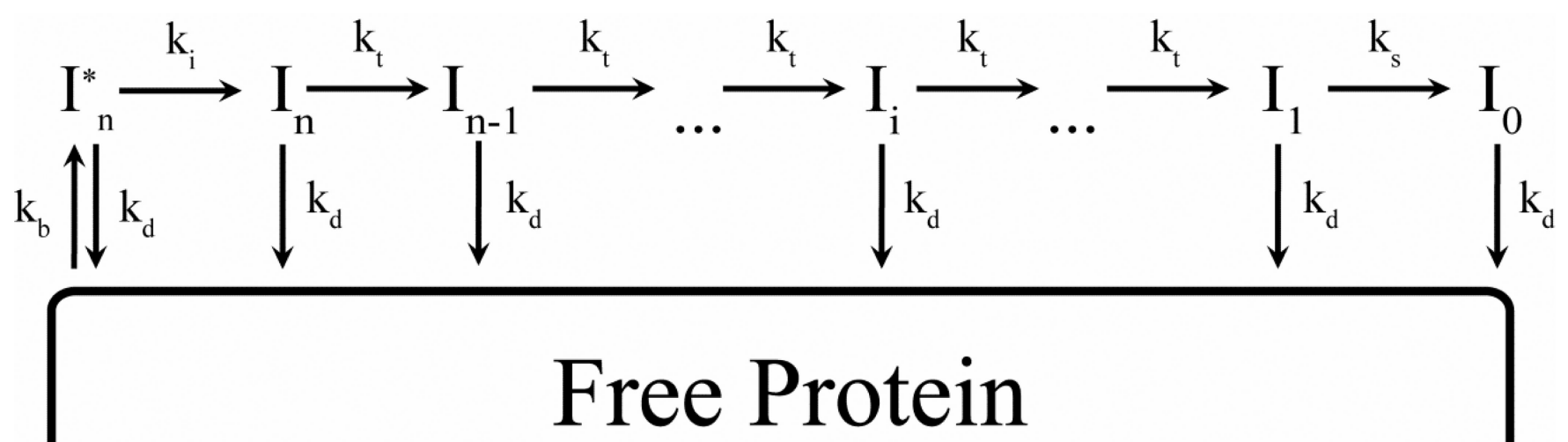

Scheme 2.

Paused-Step Streptavidin Displacement Model. A scheme built upon Scheme 1 considering an additional kinetic step where upon reaching the biotinylated end of the DNA strand, the protein encounters the streptavidin molecule and must overcome the bond strength. This results in a different microscopic rate constant at that end of the DNA, labeled $k_{S}$, and therefore includes a different controlling variable in the time-course data. 


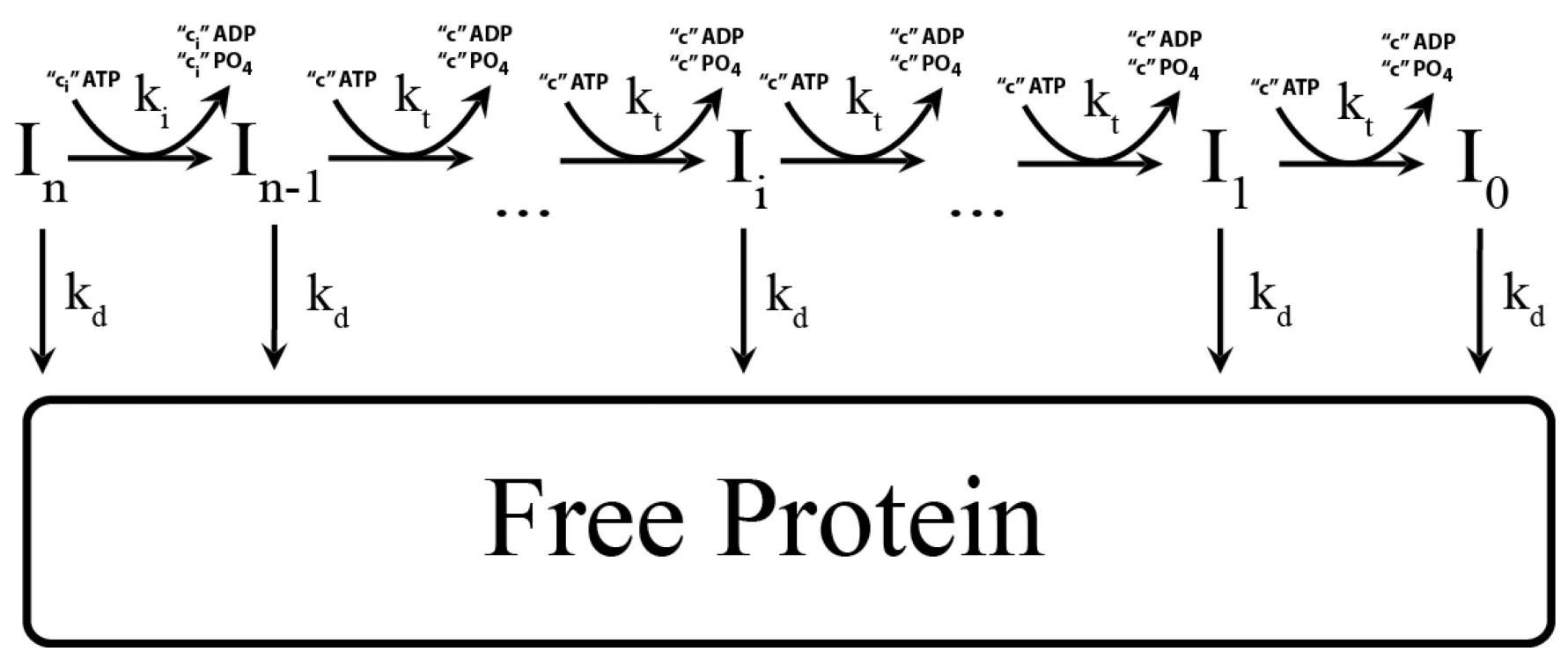

Scheme 3.

Paused-Step ADP Production Model. This model is based on Scheme 1 and is used to represent the physical understanding of Equation 4 . As the protein begins the $k_{i}$ step before processive translocation, it utilizes $c_{i}$ molecules of ATP. However, during each forward step with a rate constant $k_{t}$, the protein utilizes $c$ molecules of ATP. 
Table 1

Kinetic Parameters For DNA Translocation By RSCt.

\begin{tabular}{|c|c|c|c|}
\hline & $\begin{array}{c}\text { Pausing Step } \\
\text { Translocation Model }\end{array}$ & $\begin{array}{c}\text { Streptavidin- } \\
\text { Displacement Model }\end{array}$ & ATPase Model \\
\hline$k_{t}\left[s^{-1}\right]$ & $2.3 \pm 0.4$ & $*$ & $*$ \\
\hline$k_{d}\left[s^{-1}\right]$ & $(2.03 \pm 0.02) \times 10^{-1}$ & * & * \\
\hline$k_{i}\left[s^{-1}\right]$ & $(7.47 \pm 0.13) \times 10^{-2}$ & $*$ & $*$ \\
\hline$k_{s}\left[s^{-1}\right]$ & - & $(7.16 \pm 0.05) \times 10^{-3}$ & - \\
\hline$r$ & $1.0^{*}$ & $*$ & $*$ \\
\hline$B A$ & $-0.38 \pm 0.06$ & $*$ & - \\
\hline$m[b p]$ & $1.24 \pm 0.18$ & $*$ & $*$ \\
\hline$d[b p]$ & $14.3 \pm 0.2$ & $*$ & $*$ \\
\hline$C[A T P /$ step $]$ & - & - & $3.77 \pm 0.02$ \\
\hline$C_{i}[A T P /$ step $]$ & - & - & $11.69 \pm 0.11$ \\
\hline$C / m[A T P / b p]$ & - & - & $3.0 \pm 0.4$ \\
\hline$m^{*} k_{t}[b p / s]$ & $2.9 \pm 0.1$ & - & - \\
\hline$P$ & $0.92 \pm 0.01$ & - & - \\
\hline$\frac{P}{1-P}$ & $12 \pm 2$ & - & - \\
\hline$\frac{m^{*} P}{1-P}[b p]$ & $14.3 \pm 0.6$ & - & - \\
\hline $\begin{array}{l}\text { SSR: } \\
\text { VAR: }\end{array}$ & $\begin{array}{l}1.929 \times 10^{-3} \\
6.713 \times 10^{-7}\end{array}$ & $\begin{array}{c}1.050 \\
2.139 \times 10^{-3}\end{array}$ & $\begin{array}{c}1.729 \\
7.94 \times 10^{-3}\end{array}$ \\
\hline
\end{tabular}

Derived and Fitted Parameters For All Data Analyses. The model utilized is denoted in the column header. Starred cells are fixed parameters from the fitting of fluorescence translocation data (Column 1) and dashed marks denote parameters not included in the fitting equation. See Materials and Methods for a list of used fitting equations. 